with a lateral transfer toward the medial section of the anterior leaflet was achieved easily and without tension. This technique could also be applied to a more posterior segment of the anterior leaflet. To our knowledge, the surgical repair of bileaflet flail of the tricuspid valve has not been described. Common techniques for mitral valve repair, such as flip-over and edge-to-edge, are similarly applicable and successful in tricuspid valve repair as an alternative to tricuspid valve replacement.

\section{References}

1. Boon R, Hazekamp M, Hoohenkerk G, Rijlaarsdam M, Schoof P, Koolbergen D, et al. Artificial chordae for pediatric mitral and tricuspid valve repair. Eur J Cardiothorac Surg. 2007;32:143-8. Epub 2007 May 2.

2. Turkoz R, Gulcan O, Atalay H, Uguz E. Surgical repair of tricuspid valve regurgitation caused by blunt thoracic trauma. J Trauma. 2007;63:E7-9.

3. Kalangos A, Baldovinos A, Sezerman O, Faidutti B. Tricuspid valve repair by septal of posterior leaflet transposition. Ann Thorac Surg. 1995;60:1807-9.

4. Maisano F, Lorusso R, Sandrelli L, Torracca L, Coletti G, La Canna G, et al. Valve repair for traumatic tricuspid regurgitation. Eur J Cardiothorac Surg. 1996;10: 867-73.

\title{
Is subtotal resection of a right ventricular fibroma a valid surgical option?
}

Roland Henaine, MD, Emilie Adam, MD, Kasra Azarnoush, MD, N. Yashimura, MD, PhD, M. Cannesson, MD, A. Millon, MD,

F. Lachhab, MD, and Jean Ninet, MD, PhD, Lyon, France

We describe the case of a 40-year old woman with a right ventricular (RV) fibroma discovered after a syncopal episode, subtotal surgical resection was performed. Two years follow-up confirmed lesion stability.

\section{CLINICAL SUMMARY}

We describe the case of a 40-year old woman with a right ventricular (RV) fibroma discovered after a syncopal episode. The patient presented for a diagnostic workup after falling down during normal daily activity. The results of transthoracic echocardiography were normal. Sleep monitoring was then performed, and we concluded that the patient had narcolepsy disturbance. However, transesophageal echocardiographic analysis revealed a thickening of the intraventricular septum, bulging into the RV. Magnetic resonance imaging (MRI; Figure 1, $A$ ) showed a hypodense mass. Tumor markers were all within the normal range.

The result of a transvenous RV biopsy was normal. Thus it was decided to perform a surgical exploration through a median sternotomy. The pericardial cavity was free of ad-

From the Department of Cardiac Surgery C, Cardiologic Hospital Louis Pradel, Lyon, France.

Received for publication May 6, 2008; accepted for publication May 25, 2008.

Address for reprints: Roland Henaine, MD, Department of Cardiac Surgery C, Cardiologic Hospital Louis Pradel, Avenue du Doyen Lépine, 69394 Lyon, France

(E-mail: roland.henaine@chu-lyon.fr).

J Thorac Cardiovasc Surg 2009;137:e32-4

$0022-5223 / \$ 36.00$

Copyright (c) 2009 by The American Association for Thoracic Surgery doi:10.1016/j.jtcvs.2008.05.062

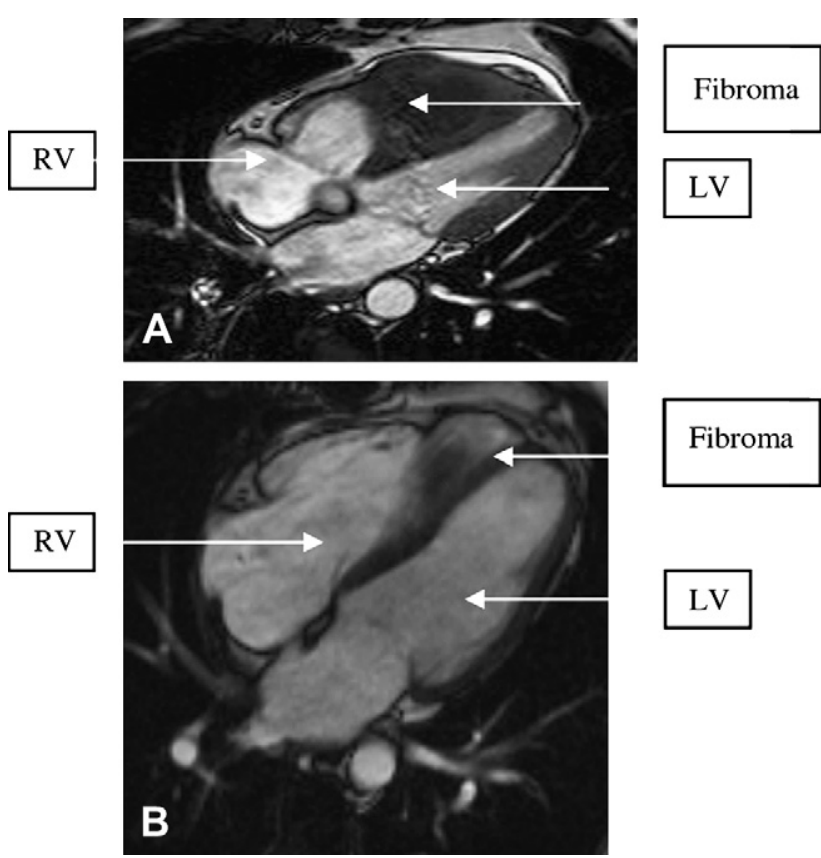

FIGURE 1. A, Preoperative magnetic resonance image: cross-section showing right interventricular fibroma from the interventricular septum. The magnetic resonance image shows a hypodense mass measuring $6 \times$ $4 \mathrm{~cm}$ located in the right ventricle, filling in all of the median and apical parts of the ventricle and spreading up to the pulmonary infundibulum close to the pulmonary valve which was widely open. Septal extension was difficult to visualizes, but the anterior pericardium seemed to be infiltrated. A pericardial effusion was also present. B, Postoperative magnetic resonance image at 2 years. $R V$, Right ventricle; $L V$, Left ventricle. 

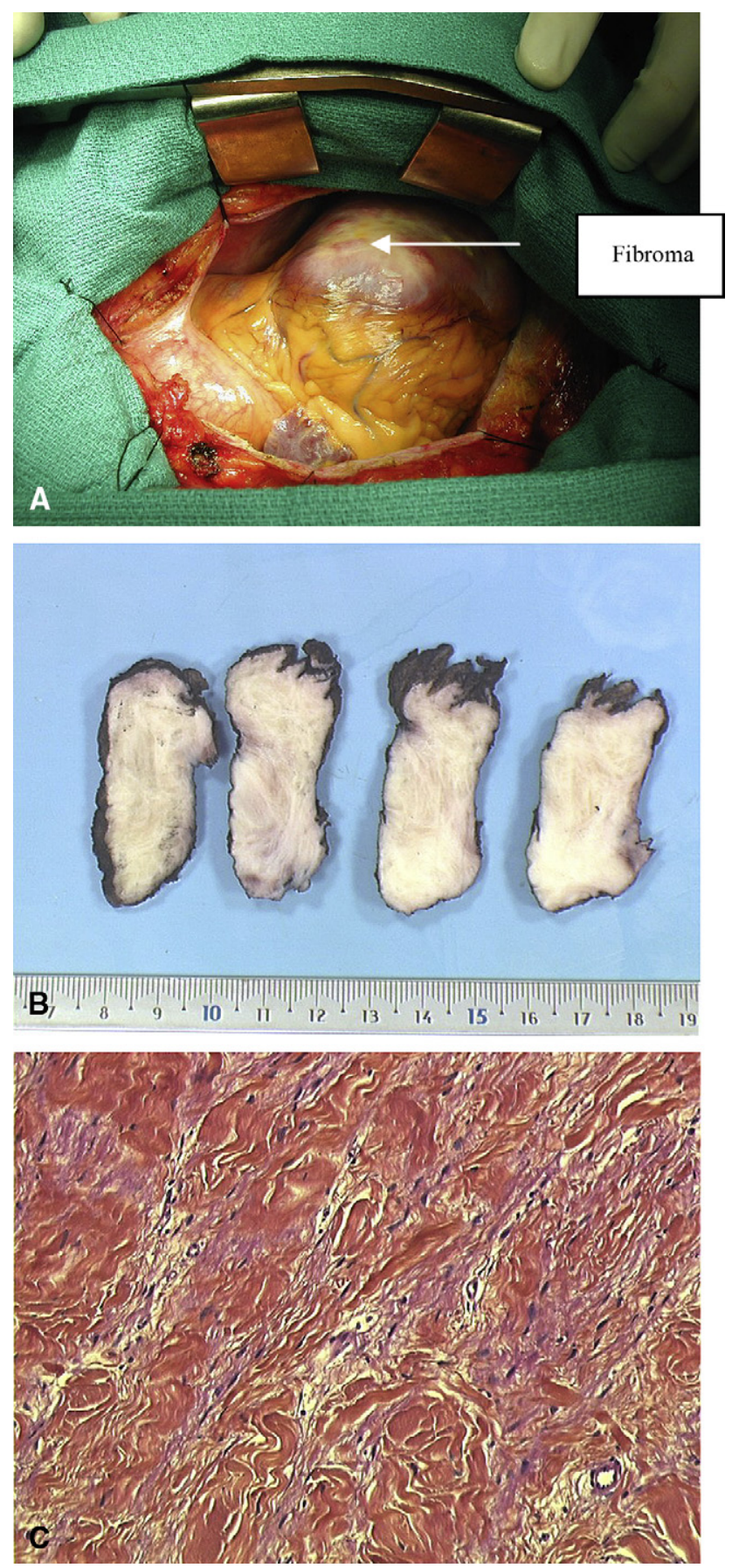

FIGURE 2. A, Surgical view. B, Macroscopic view. C, Microscopic view. Histologic section stained with hematein-eosin-saffron $\times 200$ showing monocolor proliferation composed of regular fusiform cells and separated by numerous collagen bundles.

hesion, but a lobulated tumor of the anterior RV wall was clearly evident, with the mass extending to the epicardium under the left anterior descending coronary artery and bulging into the left ventricular cavity (Figure 2, A). Histologic examination revealed a nonmalignant fibromatous tumor
(Figure 2, $B$ and $C$ ). Extracorporeal circulation was then initiated under normothermic conditions on the beating heart to reduce the tumor volume as much as possible. An incision was made through the tumor from the pulmonary ring up to the apex $3 \mathrm{~cm}$ on the right side parallel to the left anterior descending coronary artery to identify the RV cavity. The tumor measured more than $6 \mathrm{~cm}$ in diameter. After longitudinal incision, total resection of the right portion of the tumor was performed. This part was excised quite easily from the healthy myocardium. On the left side toward the septum, only the bulging part was resected because the tumor was infiltrating the interventricular septum and therefore could not be removed. However, tumor mass resection represented approximately $75 \%$ of the total tumor volume. After resection, it was possible to see the RV cavity and the outflow tract to the pulmonary artery, which was widely free with a healthy pulmonary valve. The end of extracorporeal circulation (64 minutes) was easily managed without inotropic drugs. The postoperative course was uneventful. Postoperative MRI (at day 8) showed a residual, anterior septal tumor. The patient was discharged 10 days after the operation. MRI at 1 and 2 years of follow-up confirmed lesion stability (Figure 1, $B$ ).

\section{DISCUSSION}

Cardiac fibromas are rare benign tumors developing from proliferation of fibroblasts in the connective tissue and diagnosed in the pediatric population in $80 \%$ of cases. Such tumors are usually noninvasive and nonencapsulated, but rarely, they can be infiltrative fibromas involving predominantly the left ventricle, and less than $10 \%$ of them originate from the free wall of the RV. ${ }^{1}$ Complications are related to mass compression and are represented by cardiac insufficiency and sudden death. The diagnosis is confirmed by means of histologic examination. In this case the result of the first echocardiogram was normal, although the tumor was present. However, echocardiographic analysis can lack sensitivity and specificity, and this is the reason why MRI is currently recommended as the gold standard of diagnostic imaging. ${ }^{2}$

Histologic examination has to be performed to define whether a lesion is benign or malignant to optimize treatment options (surgical intervention vs chemotherapy). Surgical exploration had to be performed because the tumor was symptomatic and the patient had a syncopal episode; this was then the only solution to improve the clinical symptomatology and prevent complications. Adjuvant treatment can be discussed based on histologic results.

Since 1962, numerous cases of total resection have been described with long-term follow-up data. ${ }^{3}$ There is agreement on the fact that surgical intervention becomes necessary when the tumor is symptomatic. However, opinions still vary regarding asymptomatic fibromas. In addition, the risk of sudden death is difficult to evaluate. Until recently, total 
resection was recommended to prevent local tumor recurrence, even if this operation impaired the patient's quality of life (bypass, valve replacement, and ventricular septal defect patch closure) ${ }^{2}$ Cases of cardiac transplantation to treat these fibromas have also been reported. ${ }^{4}$ However, subtotal resection seems to be the best therapeutic option when the size or location of the tumor makes total resection impossible. The risk of tumor regrowth seems to be relatively low. Several colleagues have described the absence of tumor progression at long-term follow-up, even if the number of cases reported is low. Finally, transplantation does not seem to be an acceptable option, even with voluminous fibromas; subtotal resection should be the treatment of choice. ${ }^{5}$

Even if it is widely accepted that fibromas should be totally resected because of their recurrence risk, subtotal surgical intervention might be an acceptable option when the volume or location of the tumor makes total resection a high-risk procedure.

\section{References}

1. Burke AP, Rosado-de-Christenson M, Templeton PA, Virmani R. Cardiac fibroma: clinicopathologic correlates and surgical treatment. $J$ Thorac Cardiovasc Surg. 1994; 108:862-70.

2. Alter P, Grimm W, Rominger MB, Ritter M, Klose KJ, Moosdorf R, et al. Right ventricular cardiac myxoma. Diagnostic usefulness of cardiac magnetic resonance imaging. Herz. 2005;30:663-7.

3. Yamaguchi M, Hosokawa Y, Ohashi H, Imai M, Oshima Y, Minamiji K. Cardiac fibroma. Long-term fate after excision. J Thorac Cardiovasc Surg. 1992;103:140-5.

4. Valente M, Cocco P, Thiene G, Casula R, Poletti A, Milanesi O, et al. Cardiac fibroma and heart transplantation. J Thorac Cardiovasc Surg. 1993;106:1208-12.

5. Cho JM, Danielson GK, Puga FJ, Dearani JA, McGregor CG, Tazelaar HD, et al. Surgical resection of ventricular cardiac fibromas: early and late results. Ann Thorac Surg. 2003;76:1929-34.

\title{
Simultaneous repair for aortic incompetence with annuloaortic ectasia and pectus excavatum by modified Ravitch procedure with pectus bars in an adult patient with Marfan syndrome
}

\author{
Yang Gi Ryu, MD, Man-Jong Baek, MD, Hyun Koo Kim, MD, Young Ho Choi, MD, Young-Sang Sohn, MD, \\ and Hark Jei Kim, MD, Seoul, Republic of Korea
}

Concomitant thoracic reconstruction in patients with Marfan syndrome, pectus excavatum, and associated aortic or cardiac surgery poses a major clinical challenge.

\section{CLINICAL SUMMARY}

A 39-year-old man was seen with dyspnea in March 2008. He had no history of musculoskeletal disease or heart disease apart from Marfanoid features according to the Ghent criteria $^{1}$ seen on general examination: kyphoscoliosis, pectus excavatum, arachnodactyly, severe myopia, and diastolic murmur on the apex. Routine laboratory values were also unremarkable. Transthoracic and transesophageal echocardiography showed severely dilated ascending aorta, severe aortic regurgitation, moderate mitral and tricuspid regurgitation, and a small type II atrial septal defect. Computed tomographic scans showed a fusiform aneurysm of the proximal

From the Department of Thoracic and Cardiovascular Surgery, Guro Hospital, Korea University Medical Center, Seoul, Republic of Korea.

Received for publication July 18, 2008; accepted for publication July 26, 2008.

Address for reprints: Man-Jong Baek, MD, Department of Thoracic and Cardiovascular Surgery, Guro Hospital, Korea University Medical Center, Guro 2-Dong, Guro-

Gu, Seoul, Republic of Korea, 152-703 (E-mail: mdmjbaek@korea.ac.kr).

J Thorac Cardiovasc Surg 2009;137:e34-6

$0022-5223 / \$ 36.00$

Copyright (c) 2009 by The American Association for Thoracic Surgery doi:10.1016/j.jtcvs.2008.07.042 ascending aorta with a maximum diameter of $73 \mathrm{~mm}$, severe pectus excavatum (pectus index of 32.6; Figure 1), thoracolumbar scoliosis, and dural ectasia of the lumbosacral area.

Surgery was initiated with a chevron submammary skin incision. The pectoralis muscles were detached from the

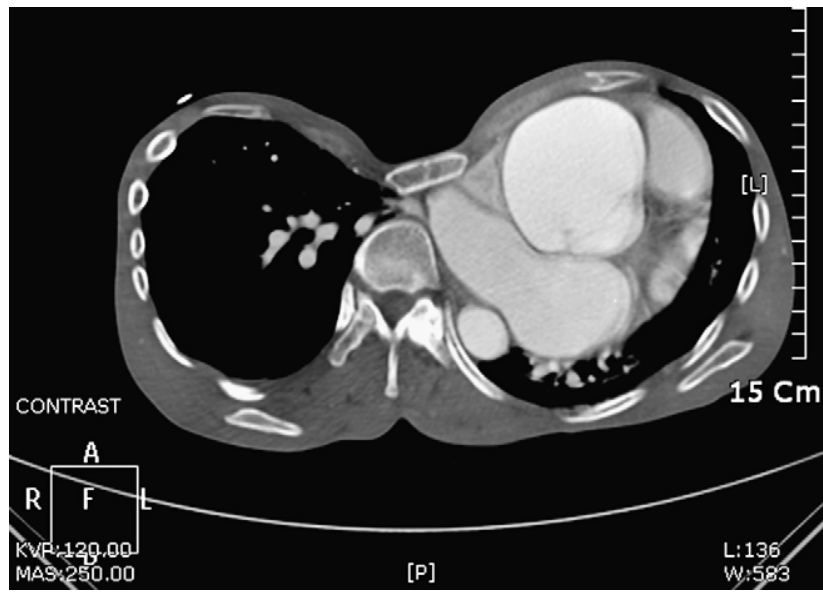

FIGURE 1. Preoperative computed tomography of pectus excavatum and annuloaortic ectasia. Axial computed tomographic scan at level of aortic root shows severe depression of sternum and marked dilatation of aortic root, with severe displacement of heart into left side of chest with compression of left lung. 